\title{
Research on Cross-Border M\&A Performance of Chinese Metallurgical Enterprises from the Perspective of LBO Financing
}

\author{
FENG Zhengqiang ${ }^{1, a}$, XIE Siman ${ }^{1, b}$
}

\author{
${ }^{1}$ School of Business, Central South University, Changsha 410083, China \\ a zhqfeng@csu.edu.cn \\ bsimanxie@163.com
}

\begin{abstract}
Based on the data of cross-border M\&As from 2005 to 2016, the effect of LBO financing on the performance of crossborder M\&A of metallurgical enterprises in China was investigated by using DID and PSM-DID estimation. Results show that LBO financing improves the market performance of Chinese metallurgical enterprises, but has no significant effect on the sustainable development ability, profitability and market share, and can significantly reduce the operational efficiency, which implies that after LBO financing, there is deviation between market performance and financial performance of Chinese metallurgical enterprises; State-owned metallurgical enterprises are more inclined to choose LBO financing, indicating that state-owned metallurgical enterprises have more external financing advantages.
\end{abstract}

Keywords: Chinese metallurgical enterprises, cross-border M\&As performance, LBO financing

\section{杜杆融资视角下的中国冶金企业跨国并购绩效研究}

\author{
冯正强 ${ }^{1, \mathrm{a}}$ ，谢斯曼 ${ }^{1, \mathrm{~b}}$
}

\footnotetext{
${ }^{1}$ 中南大学商学院, 湖南长沙, 410083

a zhqfeng@csu.edu.cn

${ }^{b}$ simanxie@163.com
}

\section{摘要}

基于 2005 年至 2016 年的跨国并购交易数据，采用双重差分法和倾向匹配双重差分法考察了杜杆融资对中国 冶金企业跨国并购绩效的影响。研究发现：杜杆融资改善了冶金企业的市场绩效，但对冶金公司的持续发展 能力、盈利能力及市场占有率无显著影响，并能显著降低冶金企业的经营效率，这说明杜杆收购融资后，我 国冶金企业的市场绩效和财务绩效存在背离状况；国有冶金企业更倾向选择杜杆融资，说明在鼓励对外投资 的政策下国有冶金企业更具有外部融资优势。

关键词: 中国冶金企业，跨国并购绩效，杜杆融资

\section{1.前言}

根据《2017 年中国对外直接投资统计公报》, 2017 年中国对外投资涉及 56 个国家和地区，实际对 外投资交易总额达 1196.2 亿美元。其中，六个行业 占中国对外直接投资总额的 $86.3 \%$, 而矿冶行业就 是六大主导行业之一。与中国冶金企业在跨国并购
中越发重要的地位形成鲜明对比的却是冶金企业跨 国并购研究的不足。因此, 本文利用双重差分法和 倾向匹配双重差分法探究了杜杆融资对中国治金企 业跨国并购绩效的影响，并尝试在以下方面做出贡 献。首先，研究我国冶金企业的跨国并购，有助于 了解我国冶金企业的跨国并购现状，弥补对中国治 金企业跨国并购的研究空白。其次，本文从融资的 
角度同时对我国冶金企业的市场绩效和财务绩效进 行研究，不仅能够多角度地和综合地评价治金企业 的跨国并购绩效，还对企业管理层的融资决策具有 现实意义。最后，结合经典融资理论和现存文献对 本研究的结果进行分析, 给我国冶金企业跨国并购 的现状提供了新的见解。

\section{2.数据来源与核心变量}

本研究以金属及金属产品为主要经营范围的中 国上市公司跨国并购交易为研究对象。跨国并购交 易数据来自于 BvD zephyr 数据库, 公告年份为 2005 年至 2016 年。剔除非深交所和上交所的上市公司交 易后, 最后可用样本为 97 宗中国上市冶金企业的跨 国并购交易。上市冶金企业的财务数据来自 CSMAR 数据库, 冶金行业数据则来自于 EPS 数据库。部分 缺失的交易数据和财务数据, 则通过查询上市公司
年报和公告获得。

本研究的被解释变量为市场绩效和财务绩效, 分别 用托宾 $\mathrm{Q}$ 衡量市场绩效以及可持续增长率、总资产 周转率、资本使用回报率、市场占有率来衡量企业 未来发展能力、企业经营效率、企业盈利能力、企 业的市场份额等财务绩效。同时, 本研究的解释变 量为杜杆收购融资。此外, 本文选取滞后一期的企 业内部特征变量作为控制变量。其中包括员工数量、 股东类型、交易价值、托宾 $\mathrm{Q}$ 、可持续增长率、总 资产周转率和投入资本回报率。由于大量的文献总 结出了股东类型对中国企业跨国并购活动的影响 [1-3], 在考虑了制度理论和 EDAMURA 和 HANEDA ${ }^{[4]}$ 提 及到的股东类型对我国企业行为影响的情况下，选 择了股东类型作为协变量。表 1 给出了各变量的描 述。

表 1 变量描述

\begin{tabular}{lll}
\hline 变量 & 定义 & 来源 \\
\hline 托宾 Q $(\mathrm{TQ})$ & 市值/总资产 & CSMAR \\
可持续增长率 $(\mathrm{SGR})$ & (净资产收益率*收益留存率) / (1-净资产收益率*收益留存率) & CSMAR \\
总资产周转率 $(\mathrm{TAT})$ & 营业收入/总资产 & CSMAR \\
资本使用回报率 $(\mathrm{RCE})$ & 息税前利润/长期资本 & CSMAR \\
市场占有率 $(\mathrm{MS})$ & 营业收入/行业总收入 & CSMAR\&EPS \\
杜杆收购融资 $(\mathrm{LB} 0)$ & 融资方式为杜杆融资时取值 1, 否则取 0 & BvD zephyr \\
员工数量 $(\mathrm{EN})$ & Log (员工数量) & CSMAR \\
股东类型 $(\mathrm{ST})$ & 国有企业为 1。反之，民营企业取值 0 & CSMAR \\
交易价值 $(\mathrm{DV})$ & $\mathrm{Log}$ (交易价值) & BvD zephyr \\
\hline
\end{tabular}

\section{3.实证检验结果}

表 2 报告了双重差分法的估计结果。结果表明 杜杆收购融资对市场绩效和经营绩效具有显著影响。 在市场绩效方面, 杜杆收购在托宾 Q 值的回归中呈 现显著的正向系数 0.216 , 这意味着采用杜杆收购融 资的中国冶金企业可以从中国股市获得正的市场回 报。这也符合从信息不对称和信号理论得出的预期, 杜杆收购融资向市场投资者发出一个积极信号, 即 企业有能力承担债务且未来的利润将超过债务融资 的成本，使企业能够负担贷款的利息。相比之下, 总资产周转率的结果并不像托宾 $\mathrm{Q}$ 值那么乐观。总 资产周转率代表了收购方企业的经营效率。由于杜 杆收购对总资产周转率的系数为负, 表明杜杆收购 与总资产周转率呈现负相关。而系数从- 0.31 降至0.64 意味着在跨国并购中采用杜杆融资的企业将面 临更差的经营效率。这与之前其他学者的研究, 杜
杆收购后经营效率将得到改善的结论相反 ${ }^{[5-8]}$ 。杜杆 收购融资导致总资产周转率下降的原因，可以经由 杜杆收购对市场占有率的不具有显著解释作用来说 明。市场占有率的结果表明，杜杆融资并未使冶金 企业的销售发生显著的变化, 即没有达到寻求市场 的目的。该结果也和 BOUCLY 和 SRAER ${ }^{[7]}$ 得出的杜 杆收购后企业的销售份额将增加的结论不同。因此, 不显著的销售变化和债务的增加共同导致了总资产 周转率的显著下降。此外, 我们也发现了杜杆收购 对可持续增长率和资本使用回报率影响不显著的证 据, 这表明杜杆收购融资对可持续发展能力和盈利 能力没有显著影响。结合以上杜杆收购对财务绩效 影响的结果, 我们得出了我国冶金企业进行杜杆收 购后财务绩效没有明显改善的结论。这一结论与其 他国家对于杜杆收购融资研究的结论相反 [7, 9-11]，也 意味着我国冶金企业对于杜杆资金的使用具有较差 的财务回报。

表 2 杜杆收购融资在跨境并购中的作用:来自 DID 的结果

\begin{tabular}{|c|c|c|c|c|c|c|c|c|c|c|c|c|}
\hline \multirow[b]{2}{*}{ \%变化 } & \multicolumn{2}{|l|}{$\mathrm{TQ}$} & \multirow[b]{2}{*}{ 到 } & \multicolumn{2}{|l|}{ SGR } & \multicolumn{3}{|l|}{ TAT } & \multicolumn{2}{|l|}{ RCE } & \multicolumn{2}{|l|}{ MS } \\
\hline & $\begin{array}{l}\text { 从 } t-1 \\
\text { 到 } t\end{array}$ & $\begin{array}{ll}\text { 从 } & t-1 \\
t+1 & \\
\end{array}$ & & $\begin{array}{l}\text { 从 } t-1 \\
\text { 到 } t\end{array}$ & $\begin{array}{ll}\text { 从 } & t-1\end{array}$ 到 & $\begin{array}{l}\text { 从 } t-1 \\
\text { 到 } t\end{array}$ & 从 $\mathrm{t}-1$ 到 & $t+1$ & $\begin{array}{l}\text { 从 } t-1 \\
\text { 到 } t\end{array}$ & $\begin{array}{l}\text { 从 } t-1 \text { 到 } \\
t+1\end{array}$ & $\begin{array}{l}\text { 从 } t-1 \\
\text { 到 } t\end{array}$ & $\begin{array}{l}\text { 从 } t-1 \text { 到 } \\
t+1\end{array}$ \\
\hline LBO & 0.088 & $0.2^{* *}$ & & -0.06 & 0.129 & $-0.3^{\text {kek }}$ & $-0.64^{* * * k}$ & & 0.102 & 0.66 & 0.108 & 0.1772 \\
\hline ST & 0.094 & 0.271 & & -0.46 & -0.82 & 0.445 & $1.14^{* * * *}$ & & -4.3 & -0.9 & -0.099 & $-1.01^{\text {***k }}$ \\
\hline DV & 0.009 & -0.03 & & -0.02 & 0.206 & 0.0314 & 0.039 & & -0.01 & 0.17 & $0.07^{* *}$ & $0.155^{\text {***k }}$ \\
\hline EN & $-0.1 * *$ & -0.11 & & 0.24 & 0.368 & $-0.11 *$ & -0.157 & & 0.216 & 0.15 & -0.096 & 0.178 \\
\hline
\end{tabular}




\begin{tabular}{lcccccccccc} 
TQ & -0.034 & -0.07 & 0.124 & 0.033 & -0.062 & -0.06 & 0.019 & 0.20 & 0.063 & 0.039 \\
SGR & -0.126 & 0.04 & -0.91 & -0.72 & $-0.51^{* *}$ & $-0.9^{* *}$ & -1.72 & -0.7 & $-0.439^{*}$ & -0.397 \\
TAT & -0.042 & 0.18 & -1.61 & -0.98 & $-1.3^{* * * *}$ & -1.944 & -0.92 & -0.2 & -0.176 & -0.085 \\
RCE & 0.179 & -0.05 & 1.477 & -0.05 & $0.742^{*}$ & 1.376 & 1.173 & -1.5 & -0.575 & -1.155 \\
N & 97 & 97 & 97 & 97 & 97 & 97 & 97 & 97 & 97 & 97 \\
\hline
\end{tabular}

表 3 汇报了倾向匹配的第一阶段 Probit 估计结 果。该结果表明股东类型对跨国并购中杜杆融资概 率具有显著影响，即国有冶金企业比民营冶金企业 更有可能在跨国并购中进行杜杆收购融资。由此可 知股东类型不仅与中国企业跨国并购的价值创造和 并购动机密切相关 ${ }^{[1,12]}$, 也影响着跨国并购中的融资 决策过程。该结果也与新兴市场以政府为主导的经 济特征一致, 在中国政府“走出去”的全球战略政策 鼓励下，国有冶金企业在进行跨国并购活动中很可 能具有外部融资优势。此外, 我国很多国有企业处 于高负债水平, 根据 DURAND 和 LAING ${ }^{[13]}$ 的研究 结论, 如果公司在跨国并购中超过了最优杜杆水平, 过度的杜杆水平将使股东面临过高的代理成本，且 代理成本将大于并购带来的任何收益。这也解释了 杜杆收购融资没有促进财务绩效改善的原因。

表 3 Probit 估计.

\begin{tabular}{ll}
\hline 股权类型 & $1.337 * *$ \\
交易价值 & 0.0227 \\
员工数量 & -0.0367 \\
托宾 Q & 0.1872 \\
可持续增长率 & 0.5934 \\
总资产周转率 & 0.6398 \\
资本使用回报率 & -1.4843 \\
样本数量 & 97 \\
$\mathrm{R}^{2}$ & 0.07 \\
\hline
\end{tabular}

注: * *** ****分别为 $10 、 5 、 1 \%$ 水平的统计学显著 性。

表 4 给出了经过 PSM 估计后进行的 DID 估计结 果。可见, PSM-DID 估计得到的结果与简单的 DID 估计结果一致, 即杜杆收购对市场绩效和经营绩效 的具有显著的影响。杜杆收购对于托宾 $\mathrm{Q}$ 的影响是 显著正向的，同时杜杆收购公司的托宾 $\mathrm{Q}$ 也更为正 向，一个季度期间为 0.087 , 两个季度期间则为 0.191 ，而非杜杆收购公司则一个季度期间为 0.008 , 两个季度期间为 -0.07 。换句话说，股票市场的投资 者对杜杆收购融资公司的未来绩效是乐观的。与此 相反的是杜杆收购对总资产周转率的影响是显著负 向的。杜杆融资公司的总资产周转率在两个季度内 从 0.726 直接下降到 0.189 , 且杜杆收购对 -0.537 的差 异具有显著影响。因此, 我们在双重差分法估计中 得出的结果通过 PSM-DID 的检验后是具有稳健性的。 这两种方法所得出的一致结果可以保证我们结论的 可靠性。考虑到我国冶金企业的跨国并购肩负着我 国金属资源安全的战略任务，并且进行杜杆并购融 资的冶金企业也主要为国有冶金企业，因此，市场 绩效和财务绩效的背离的状况和资本市场上投资者 对于国家战略布局的支持态度是密不可分的。

表 4 PSM-DID 估计

\begin{tabular}{|c|c|c|c|c|}
\hline 绩效变量 & 时期 & 非杜杆融资公司 (\% 变化) & 杜杆融资公司 (\% 变化) & 杜杆融资的影响 \\
\hline \multirow{3}{*}{ 托宾 Q } & 从 $t-1$ 到 $t$ & 0.008 & 0.087 & 0.079 \\
\hline & 从 $t-1$ 到 & & & \\
\hline & $t+1$ & -0.07 & 0.191 & $0.261 * * *$ \\
\hline \multirow{3}{*}{ 可持续增长率 } & 从 $\mathrm{t}-1$ 到 $\mathrm{t}$ & 0.224 & 0.22 & -0.004 \\
\hline & 从 $t-1$ 到 & & & \\
\hline & $t+1$ & 0.082 & 0.476 & 0.394 \\
\hline \multirow{3}{*}{ 总资产周转率 } & 从 $\mathrm{t}-1$ 到 $\mathrm{t}$ & 0.472 & 0.203 & -0.268 \\
\hline & 从 $t-1$ 到 & & & \\
\hline & $t+1$ & 0.726 & 0.189 & $-0.537 * * *$ \\
\hline \multirow{3}{*}{ 资本使用回报率 } & 从 $t-1$ 到 $t$ & 0.029 & 0.018 & -0.011 \\
\hline & 从 $t-1$ 到 & & & \\
\hline & & -0.177 & 0.196 & 0.374 \\
\hline \multirow{3}{*}{ 市场占有率 } & 从 $\mathrm{t}-1$ 到 $\mathrm{t}$ & 0.111 & 0.242 & 0.131 \\
\hline & 从 $t-1$ 到 & & & \\
\hline & $t+1$ & 0.322 & 0.469 & 0.147 \\
\hline
\end{tabular}

注: * **、***分别为 $10 、 5 、 1 \%$ 水平的统计学显著性。

\section{4.研究结论与启示}

本研究以 97 家中国冶金企业为研究对象, 研究
了杜杆收购对跨国并购市场绩效和财务绩效的影响。 由于最终适用样本的规模较小和为了控制内生性偏 差, 因此我们首先使用了双重差分法进行估计, 之 
后我们进一步使用了倾向匹配双重差分法 (PSMDID）来保证双重差分法(DID)估计结果的稳健性。 这两种方法的估计结果具有一致性, 因此意味着我 们的结论是可靠的。我们得出了以下主要结果:

1）国有治金企业在跨国并购中更倾向于使用杜 杆收购融资，这意味着股东类型不仅与我国跨国并 购的价值创造、并购动机密切相关，而且影响着跨 国并购的融资决策。在鼓励企业走出去的政策下， 国有冶金企业更具有外部融资的优势。

2）在跨国杜杆收购后中国治金企业的市场绩效 有所改善，这表明中国股市的投资者对冶金企业跨 国并购中的杜杆融资持有乐观态度和美好的期望。

3) 财务绩效则不如市场绩效乐观。杜杆收购后 的冶金企业经营效率得到恶化，此外，杜杆收购对 我国冶金企业跨国并购的可持续发展能力、盈利能 力和市场占有率均无显著影响。杜杆收购对中国冶 金企业在跨国并购中的财务绩效没有激励作用。与 西方其他国家杜杆收购的绩效相比, 我国冶金企业 杜杆融资的财务绩效差强人意。

4）在进行杜杆并购融资的冶金企业主要为国有 冶金企业的情况下，国有冶金企业的高负债率使并 购企业无法享受到杜杆收购融资在财务绩效方面带 来的收益。此外, 我国冶金企业肩负着保护我国金 属资源安全的重大任务, 其跨国杜杆并购后, 市场 绩效和财务绩效的背离状况和资本市场上投资者对 于冶金企业的跨国并购战略意义和市场预期是密不 可分的。

杜杆收购融资对跨国并购绩效的影响揭示了融 资决策在跨国并购中的重要意义。对于中国冶金企 业来说, 其杜杆融资的财务回报有待提高。我国冶 金企业管理层在进行融资决策时，首先应该明确并 购动机和目标, 再结合自身财务状况并综合考虑融 资策略对跨国并购绩效的影响。在跨国并购中考虑 使用杜杆融资时, 我国冶金企业需要关注杜杆资金 的使用成本和回报, 并需要合理评估杜杆资金使用 的可行性, 建立动态项目管理模式, 能随时监测杜 杆资金使用状况并核算资金使用成本。国有冶金企 业应该继续深化改革, 加强 “去杜杆” 化, 在跨国 并购中合理地利用自身融资优势。此外, 我国也应 该加强民营企业在跨国并购中的融资便利性, 为民 营企业的海外投资和发展提供资源。

\section{REFERENCES}

[1] DU, M. and A. BOATENG, State Ownership, Institutional Effects and Value Creation in CrossBorder Mergers \& Acquisitions by Chinese Firms [J]. International Business Review, 2015. 24(3): p. 430-442.
[2] CHEN, Y.Y. and M.N. YOUNG, Cross-Border Mergers and Acquisitions by Chinese Listed Companies: A Principal-Principal Perspective [J]. Asia Pacific Journal of Management, 2010. 27(3): p. 523-539.

[3] LI, J. and Z. XIE, Examining the Cross-Border Acquisition Strategy of Chinese Companies [J]. Journal of Leadership \& Organizational Studies, 2013. 20(4): p. 436-447.

[4] EDAMURA, K., et al., Impact of Chinese CrossBorder Outbound M\&as on Firm Performance: Econometric Analysis Using Firm-Level Data is [J]. China Economic Review, 2014. 30(C): p. 169-179.

[5] AXELSON, U., et al., Borrow Cheap, Buy High? The Determinants of Leverage and Pricing in Buyouts [J]. The Journal of Finance, 2013. 68(6): p. 22232267.

[6] WEIR, C., P. JONES, and M. WRIGHT, Public to Private Transactions, Private Equity and Performance in the Uk: An Empirical Analysis of the Impact of Going Private [J]. 2008.

[7] BOUCLY, Q., D. SRAER, and D. THESMAR, Growth Lbos [J]. Journal of Financial Economics, 2011. 102(2): p. 432-453.

[8] BERGSTRöM, C., M. GRUBB, and S. JONSSON, The Operating Impact of Buyouts in Sweden: A Study of Value Creation [J]. The journal of Private equity, 2007. 11(1): p. 22.

[9] COLLA, P., F. IPPOLITO, and H.F. WAGNER, Leverage and Pricing of Debt in Lbos [J]. Journal of Corporate Finance, 2012. 18(1): p. 124-137.

[10] COHN, J.B., L.F. MILLS, and E.M. TOWERY, The Evolution of Capital Structure and Operating Performance after Leveraged Buyouts: Evidence from Us Corporate Tax Returns [J]. Journal of Financial Economics, 2014. 111(2): p. 469-494.

[11] CUMMING, D., D.S. SIEGEL, and M. WRIGHT, Private Equity, Leveraged Buyouts and Governance is [J]. Journal of Corporate Finance, 2007. 13(4): p. $439-460$.

[12] DENG, P., Why Do Chinese Firms Tend to Acquire Strategic Assets in International Expansion? [J]. Journal of World Business, 2009. 44(1): p. 74-84.

[13] DURAND, R.B., E. LAING, and M.T. NGO, The Disciplinary Role of Leverage: Evidence from East Asian Cross-Border Acquirers' Returns is [J]. Finance Research Letters, 2016. 18: p. 83-88. 